\title{
Synthesis of $\mathrm{FePO}_{4}$ Precursor for $\mathrm{LiFePO}_{4}$ Battery Cathode from Used Nickel Plated A3 Steel Battery Shell by Hydrometallurgy Processing
}

\author{
R. Aisyah ${ }^{1}$, S.T. Samudera ${ }^{1}$, A. Jumari ${ }^{1,2,}$, , A. Nur ${ }^{1,2}$ \\ 1. Department of Chemical Engineering, Faculty of Engineering, Universitas Sebelas Maret, \\ Jl. Ir. Sutami 36 A, Surakarta, Central Java 57126, Indonesia \\ 2. Centre of Excellence for Electrical Energy Storage Technology, Universitas Sebelas Maret, \\ Jl. Slamet Riyadi 435, Surakarta 57146, Indonesia \\ * corresponding author : arifjumari ft@staff.uns.ac.id \\ Received : 22-10-2020; Revised : 01-02-2021; Accepted : 08-08-2021; Published : 01-12-2021
}

\begin{abstract}
One of the most well-known material for lithium battery cathode synthesis of lithium ferro-phosphate type is iron phosphate precursor. The precursor is synthesized by the use of leaching method with tartaric acid solution with optimization at various leaching temperature and time. The temperature variables are at $30{ }^{\circ} \mathrm{C} 50^{\circ} \mathrm{C} 70{ }^{\circ} \mathrm{C}$ and $90{ }^{\circ} \mathrm{C}$. The time variables are at 3 hours, 6 hours, and 9 hours. The main material that is used is iron from used nickel plated A3 steel battery shell. The recovered iron concentration and quantity is calculated from absorbance by atomic absorption spectrophotometry (AAS). AAS analysis indicates the absorbed Fe is rated at $1,02 \%\left(30^{\circ} \mathrm{C} 2,76 \%\left(50^{\circ} \mathrm{g}, 9,93 \%\left(70^{\circ} \mathrm{g}\right.\right.\right.$, and $34,31 \%$ $\left(90^{\circ} \mathrm{O}\right.$ during 9 hours of leaching.The analysis indicates the recovered iron is rated the highest during 9 hours of leaching at the highest temperature. X-ray diffraction analysis at various leaching temperature variable indicates formation of iron phosphate crystal to be compared with iron phosphate commercial precursor, while scanning electron microscope analysis shows uniform iron phosphate particle morphology.
\end{abstract}

Keywords: Lithium battery cathode, iron phosphate, Leaching, Atomic absorption, spectrophotometry, X-ray diffraction.

\section{Introduction}

In this era of globalization, the use of electronic devices, such as cellular phone, portable computer, and many others saw significant increase, prompting the development of efficient, electrical energy storage device (in this case, battery) that economical, high-capacity, as well as being made from materials that are environmentally friendly and easily obtained. Example of batteries that have seen widespread use on portable devices currently are lithium-ion batteries (LIBs), such as on cellular phones, personal computer, video cameras, and also motorized vehicle in this modern days. Due to being able to fulfil the desired characteristics, such as small weight and 
size, high voltage, low energy release velocity with high energy density is what makes LIBs can be used as alternatives for fossil fuel today [1,2].

As one of secondary battery cathode materials, lithium iron phosphate or also known as $\mathrm{LiFePO}_{4}$ had shown good performances and widespread use in their applications at electric motor vehicles at moderate to higher capacity due to lower cost, non-toxic, and high theoretical capacity (170 $\left.\mathrm{mAhg}^{-1}\right)$, and good cyclic performance [3].

Hydrometallurgy is a widespread leaching method that can also be used to recycling LIBs. It involves leaching process from cathode material obtained from the first step, by selectively separating the metal from leaching solution, thus can be obtained in pure condition at various condition. In this process, Liu (2017)[4] demonstrated the recovery of $\mathrm{Li}$ from used $\mathrm{LiFePO}_{4}$ batteries with the use of $\mathrm{H}_{2} \mathrm{SO}_{4}$ (often supported with $\mathrm{H}_{2} \mathrm{O}_{2}$ as oxidant) and some organic acids to perform the leaching method of all material elements inside the solution into cathode materials followed by separation process by chemical precipitant $(\mathrm{NaOH})$. Chen et.al (2014) also uses $\mathrm{H}_{2} \mathrm{SO}_{4}$ to extract lithium from other types of lithium batteries as well [5].

Li (2017) demonstrates the reaction between $\mathrm{Fe}$ ions and $\mathrm{H}_{2} \mathrm{SO}_{4}$ with $\mathrm{H}_{2} \mathrm{O}_{2}$ presence as follows [4]:

$$
2 \mathrm{Fe}^{2+}+\mathrm{H}^{2} \mathrm{O}^{2}+2 \mathrm{H}^{+} \rightarrow 2 \mathrm{Fe}^{3+}+2 \mathrm{H}^{2} \mathrm{O}
$$

While Zhang et.al. demonstrated the reaction as [6]:

$$
\begin{aligned}
& \mathrm{Fe}^{2} \mathrm{O}_{(\mathrm{s})}+6 \mathrm{H}^{+} \rightarrow 2 \mathrm{Fe}^{3+}+3 \mathrm{H}^{2} \mathrm{O}_{(\mathrm{l})} \\
& \Delta \mathrm{G}=-130.300 \mathrm{~J} / \mathrm{mole} \\
& \mathrm{Fe}_{3} \mathrm{O}_{4(\mathrm{~s})}+6 \mathrm{H}+\rightarrow 2 \mathrm{Fe}_{3+}+3 \mathrm{H}_{2} \mathrm{O}_{(\mathrm{l})} \\
& \Delta \mathrm{G}=-211.120 \mathrm{~J} / \mathrm{mole}
\end{aligned}
$$

However, it was found that excessive addition of acid to all metal elements, leading to high acid concentration (from 2M up to $6 \mathrm{M}$ ) caused the separation process required significant amount of base to neutralize it. The leaching separation method with molar ratio $\mathrm{LiFePO}_{4}: \mathrm{H}_{2} \mathrm{SO}_{4}$ : $\mathrm{NaOH}$ at 1: 8: 15 indicates that $\mathrm{H}_{2} \mathrm{SO}_{4}$ addition would be 16 times as much than the stoichiometric value. He et.al. (2010) was able to recover up to $65 \%$ of iron from pyrite cinder leaching solution by the use of $\mathrm{H} 2 \mathrm{SO} 4$ at pH 7.0 (based on optimum operating parameter) and $\mathrm{NaOH}$ ranging from $1 \mathrm{M}$ to $5 \mathrm{M}$ as neutralizing base[7]. However, the need for $\mathrm{NaOH}$ for the neutralization was about 0,06 gram per gram sample [7]. Assuming that the leaching result is treated by $\left(\mathrm{NH}_{4}\right)_{2} \mathrm{H}_{2} \mathrm{PO}_{4}$ and $\mathrm{H}_{2} \mathrm{O}_{2}$ then dried, the cost of both acid and neutralizing base would be high as well.

For these reasons, several weak acids are also used, such as organic acids [8] among them are citric acid, malic acid [9], tartaric acid [10], and formic acid to recycle the iron from the battery shell. In this research, as it was found that tartaric acid was the most effective, the $\mathrm{FePO}_{4}$ precursor synthesis was done by leaching of battery shell consisted mainly of iron by the use of tartaric acid. In this method, $\mathrm{Fe}_{2+}$ ions from the shells are dissolved within the tartaric acid solution, later treated by the use of $5 \%$ $\mathrm{H}_{2} \mathrm{O}_{2}$ and $\left(\mathrm{NH}_{4}\right)_{2} \mathrm{H}_{2} \mathrm{PO}_{4}$ powder [11].

\section{Experimental Method}

\subsection{Materials}

Raw materials used in this research included: Used Nickel-Plated A3 steel battery shells, tartaric acid, distilled water, $5 \%$ mole $\mathrm{H}_{2} \mathrm{O}_{2}$, and $\left(\mathrm{NH}_{4}\right)_{2} \mathrm{H}_{2} \mathrm{PO}_{4}$ powder (ACS, Reag. Ph Eur, Merck)

\subsection{Methodology \\ Materials and reagents. Raw materials used in this research included: Used Nickel-}


Plated A3 steel battery shells, tartaric acid, distilled water, $5 \%$ mole $\mathrm{H}_{2} \mathrm{O}_{2}$, and $\left(\mathrm{NH}_{4}\right)_{2} \mathrm{H}_{2} \mathrm{PO}_{4}$ powder.

Experimental procedures.

(1) Creating 1,5 M tartaric acid solution at $100 \mathrm{ml}$ by diluting 22,5 grams of the acid into the distilled water.

(2) Leaching of the shell. The leaching process was done by chipping the used shells, 5 grams each, for each leaching temperature variable at $30^{\circ} \mathrm{C} 50^{\circ} \mathrm{C} 70^{\circ} \mathrm{C}$ and $90^{\circ} \mathrm{C}$

(3) Dissolving the chipped shell into the tartaric acid solution inside the beaker and stirring it continuously at $500 \mathrm{rpm}$ for period of 3, 6 and 9 hours. During the leaching period $25 \mathrm{~mL}$ samples were taken for each leaching temperature and period.

(4) After those samples were taken, those samples were diluted 5000 times. AAS analysis were performed to determine the $\mathrm{Fe}$ content on each samples.

(5) Weight measurement of leached iron and reacting $\left(\mathrm{NH}_{4}\right)_{2} \mathrm{H}_{2} \mathrm{PO}_{4}$ stoichiometrically with the leaching solution product (mole ratio 1:1). Then $\mathrm{H}_{2} \mathrm{O}_{2}$ were added at $5 \mathrm{ml}$ to each analyzed solution until yellowish-white deposits were formed. Next is filtering those deposits and washing them with warm water $\left(50^{\circ} \mathrm{g}\right.$. After that, those deposits were dried by the use of oven and measuring the weight of the dried $\mathrm{FePO}_{4}$.

(6) XRD analysis and SEM is performed to analyze the synthesized $\mathrm{FePO}_{4}$ crystal particle and morphology system.

\section{Result and Discussion}

3.1. Analysis of recovered Fe concentration by AAS

AAS analysis result of diluted leaching solution with leaching temperature of $30^{\circ} \mathrm{C}$, $50^{\circ} \mathrm{C} 70^{\circ} \mathrm{C} 90^{\circ} \mathrm{C}$ and period of 3,6 , and 9 hours is shown in Figure 1. Each leaching temperature and period show different $\mathrm{Fe}$ absorbance levels, where AAS analysis result shows extracted Fe of $1,02 \%\left(30^{\circ} \mathrm{O}\right.$; $2,76 \%\left(50^{\circ} \mathrm{g} ; 9,93 \%\left(70^{\circ} \mathrm{g}\right.\right.$; and $34,31 \%$ $\left(90^{\circ} \mathrm{G}\right.$ by leaching period of 9 hours.

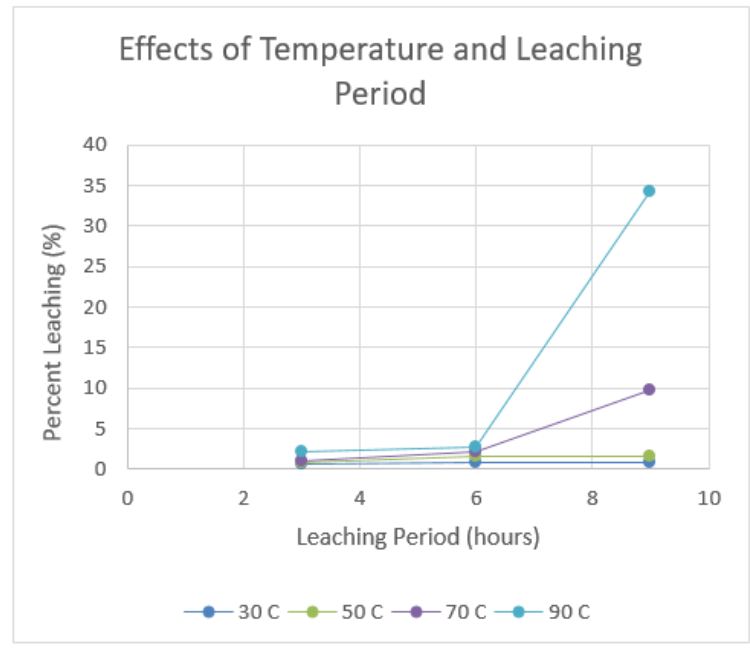

Figure 1. AAS analysis on Fe Leaching at temperature $30^{\circ} \mathrm{C} 50^{\circ} \mathrm{C} 70^{\circ} \mathrm{C}$ and $90^{\circ} \mathrm{Cat}$ periods of 3,6 , and 9 hours

AAS analysis shows that the higher the temperature and the longer the leaching period, the bigger the $\mathrm{Fe}^{2+}$ ion concentration dissolved in the acid solution. From the analysis, the highest concentration of dissolved $\mathrm{Fe}^{2+}$ at $34,31 \%$ was achieved during 9 hours of leaching period at $90^{\circ} \mathrm{C}$

3.2. $\mathrm{FePO}_{4}$ Analysis by XRD (X- ray Diffraction)

$\mathrm{XRD}$ analysis aims to determine crystal system from $\mathrm{FePO}_{4}$ sample. It shows the formation of $\mathrm{FePO}_{4}$. XRD analysis result is shown on Figure 2:

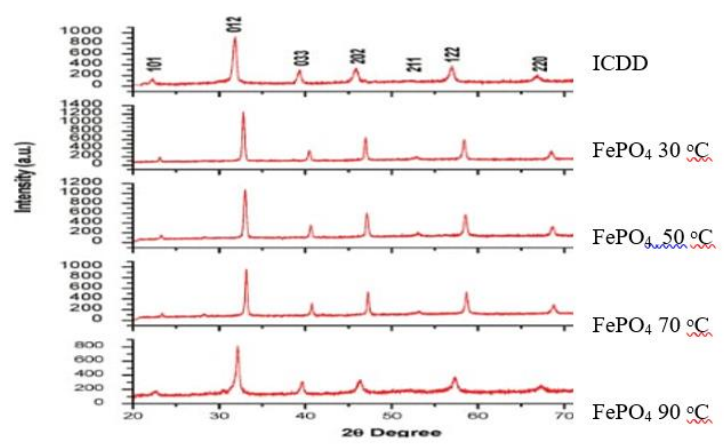

Figure 2. $\mathrm{FePO}_{4}$ characterization using XRay Diffraction at leaching temperature of $30{ }^{\circ} \mathrm{C} 50{ }^{\circ} \mathrm{C} 70{ }^{\circ} \mathrm{C}$ dan $90^{\circ} \mathrm{C}$ 
Table 1. Analysis result with lattice parameter

\begin{tabular}{ccc}
\hline Variable & $\mathrm{I}(012) / \mathrm{I}(122)$ & $\mathrm{R}$ \\
\hline FeP04 $30^{\circ} \mathrm{C}$ & 1,79 & 0,497 \\
\hline FeP04 $50^{\circ} \mathrm{C}$ & 1,85 & 0,420 \\
\hline FeP04 $70{ }^{\circ} \mathrm{C}$ & 1,91 & 0,432 \\
\hline FeP04 $90^{\circ} \mathrm{C}$ & 2,26 & 0,399
\end{tabular}

The higher I(012)/I(122) ratio, the lower cation mixing degree of cathode material. Measurement result indicates I(012) peak height compared to I(122) gives ratio number of more than 1.2. The lattice parameter requirement shows the oxidation on iron $(\mathrm{Fe} 2+$ to $\mathrm{Fe} 3+)$ until it is stabilized, while lower $\mathrm{R}$ factor value, indicated as lower than 0,44 shows that the component is well-distributed [12].

XRD quantitative result of $\mathrm{FePO} 4$ powder synthesized by tartaric acid leaching at $50^{\circ} \mathrm{Cto} 90^{\circ} \mathrm{Cshows}$ uniformity, as shown by 3 peaks with similar position but with slight difference on each peaks. These 3 peaks show the formation of $\mathrm{FePO}_{4}$ complying to $\mathrm{FePO}_{4}$ cathode International Centre for Diffraction Data (ICDD) in general. This means that $\mathrm{FePO}_{4}$ had been synthesized, although the leaching temperature of $30^{\circ} \mathrm{Conly}$ shows little $\mathrm{FePO}_{4}$ formation.

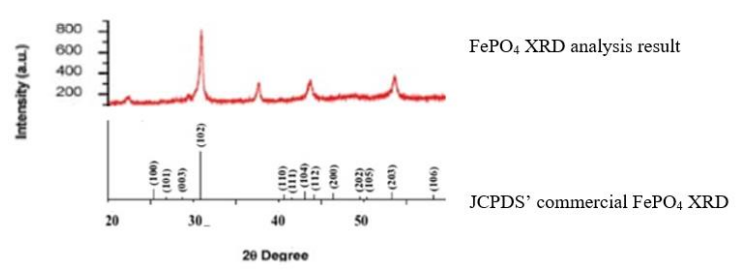

Figure 3. Analysis result of $\mathrm{FePO}_{4} \mathrm{XRD}$ to commercial $\mathrm{FePO}_{4}$ comparison

Comparing the analysis of synthesized $\mathrm{FePO}_{4}$ to JCPDS commercial $\mathrm{FePO}_{4}$ precursor shows the of diffraction angle and [2] intensity is almost the same. This shows that $\mathrm{FePO}_{4}$ with properties similar to commercial $\mathrm{FePO}_{4}$ had been synthesized at the leaching temperature and period. However, a peak at $38^{\circ}$ diffraction angle is unsuitable with commercial $\mathrm{FePO}_{4}$ precursor. It can be said that $\mathrm{FePO}_{4}$ synthesis result by the use of tartaric acid leaching gives impurity in form of $\mathrm{Fe}(\mathrm{OH})_{3}$ as by-product of iron hydrolysis in acid solution [13].

\section{Conclusions}

In this research, $\mathrm{FePO}_{4}$ is synthesized by varying the leaching temperature and period. Leaching temperature is $30^{\circ} \mathrm{C}, 50^{\circ} \mathrm{C}$, $70^{\circ} \mathrm{C}$ and $90^{\circ} \mathrm{C}$, while leaching periods are 3 , 6 , and 9 hours. AAS analysis indicates that synthesis is the most effective at $90^{\circ} \mathrm{C}$ and leaching period of 9 hours, with the extracted $\mathrm{Fe}$ of $34,31 \%$. XRD analysis indicates optimum $\mathrm{FePO}_{4}$ formation at the same temperature and period, indicated by diffraction angle and intensity that is almost the same with JCPDS $\mathrm{FePO}_{4}$ commercial precursor.

\section{Acknowledgment:}

The authors expressed their gratitude to Centre of Excellence for Electrical Energy Storage Technology (CE-FEEST), Universitas Sebelas Maret for providing research facility and the raw material. The authors thanked the university and other colleagues, especially Mr. Arif, Mr. Agus, and students from diploma department, for providing the assistance to provide the materials needed, as well as sending some of the samples to UII to be identified. Also, the author thanks laboratory assistant Cornell, which is without his help, we would not be able to perform the research during our Community Services' program.

\section{References}

[1] P.P. Prosini, Iron Phosphate Materials as Cathodes for Lithium Batteries, 2011. https://doi.org/10.1007/978-0-85729745-7.

P. Yadav, C.J. Jie, S. Tan, M. Srinivasan, Recycling of cathode from spent lithium iron phosphate batteries, J. Hazard. Mater. 399 (2020) 123068. 
https://doi.org/10.1016/j.jhazmat.2020. 123068.

[3] D. Anseán, M. González, V.M. García, J.C. Viera, J.C. Antón, C. Blanco, Evaluation of [9] LiFePO4 Batteries for Electric Vehicle Applications, IEEE Trans. Ind. Appl. (2015). https://doi.org/10.1109/TIA.2014.2344 446.

[4] H. Li, S. Xing, Y. Liu, F. Li, H. Guo, G. Kuang, Recovery of Lithium, Iron, and Phosphorus from Spent LiFePO4 Batteries Using Stoichiometric Sulfuric Acid Leaching System, ACS Sustain. Chem. Eng. (2017). https://doi.org/10.1021/acssuschemen g.7b01594.

[5] X. Chen, Y. Chen, T. Zhou, D. Liu, H. Hu, S. Fan, Hydrometallurgical recovery of metal values from sulfuric acid leaching liquor of spent lithium-ion batteries, Waste Manag. 38 (2015) 349-356. https://doi.org/10.1016/j.wasman.2014 .12.023.

[6] J. Zhang, W. Sun, F. Niu, L. Wang, Y. Zhao, M. Han, Atmospheric sulfuric acid leaching thermodynamics from metallurgical zinc-bearing dust sludge, Int. J. Heat Technol. (2018). https://doi.org/10.18280/ijht.360131.

[7] B. He, X. Tian, Y. Sun, C. Yang, Y. Zeng, Y. Wang, S. Zhang, Z. Pi, Recovery of iron oxide concentrate from high-sulfur and low-grade pyrite cinder using an innovative beneficiating process, Hydrometallurgy. 104 (2010) 241-246. https://doi.org/10.1016/j.hydromet.201 0.06 .009 .

[8] P.G. Tzeferis, S. Agatzini-Leonardou, Leaching of nickel and iron from Greek non-sulphide nickeliferous ores by organic acids, Hydrometallurgy. (1994). https://doi.org/10.1016/0304386X(94)90031-0.

L. Li, J.B. Dunn, X.X. Zhang, L. Gaines, R.J. Chen, F. Wu, K. Amine, Recovery of metals from spent lithium-ion batteries with organic acids as leaching reagents and environmental assessment, J. Power Sources. 233 (2013) 180-189.

https://doi.org/10.1016/j.jpowsour.201 2.12.089.

[10] L.P. He, S.Y. Sun, Y.Y. Mu, X.F. Song, J.G. $\mathrm{Yu}$, Recovery of Lithium, Nickel, Cobalt, and Manganese from Spent Lithium-Ion Batteries Using l-Tartaric Acid as a Leachant, ACS Sustain. Chem. Eng. 5 (2017) 714-721.

https://doi.org/10.1021/acssuschemen g.6b02056.

[11] T. Wang, Y. Yin, H.W. Liu, Synthesis of FePO4 from FePO4 and its application in synthesizing cathode material LiFePO4, Wuji Cailiao Xuebao/Journal Inorg. Mater. (2013). https://doi.org/10.3724/SP.J.1077.2013. 12178.

[12] K. Wu, F. Wang, L. Gao, M.R. Li, L. Xiao, L. Zhao, S. Hu, X. Wang, Z. Xu, Q. Wu, Effect of precursor and synthesis temperature on the structural and electrochemical properties of Li(Ni 0.5Co 0.2Mn 0.3)O 2, Electrochim. Acta. 75 (2012) 393-398. https://doi.org/10.1016/j.electacta.201 2.05.035.

[13] G. Cai, K.Y. Fung, K.M. Ng, C. Wibowo, Process development for the recycle of spent lithium ion batteries by chemical precipitation, Ind. Eng. Chem. Res. (2014). https://doi.org/10.1021/ie5025326. 